\title{
JUNTAS, TERTULIAS Y CONSPIRACIÓN EN LA CRISIS DEL RÉGIMEN ISABELINO. EL CASO DE LA CIUDAD DE BARCELONA, 1867-1868*
}

\author{
por \\ JOSEP PiCh I MitJANA \\ Universitat Pompeu Fabra, Barcelona
}

RESUMEN: Se estudia la organización y la actividad de los revolucionarios barceloneses en el periodo previo al triunfo de la Revolución Democrática de 1868. Las memorias no publicadas de A. Feliu Codina nos ban servido para reconstruir la actividad de los opositores al régimen de Isabel II en la capital catalana. Éstas nos proporcionan datos inéditos del funcionamiento, organización y actividades de los centros revolucionarios barceloneses, y de la Junta revolucionario clandestina constituida desde 1867. En Barcelona, donde el movimiento juntista no era mayoritariamente republicano ni conscientemente federalista, pero los preparativos y el estallido de la revolución de 1868 transformaron lo que inicialmente era un pronunciamiento en una verdadera Revolución Democrática y a Barcelona en la pionera del republicanismo federal español.

PALABRAS Clave: Revolución de 1868. Organización de los revolucionarios. Juntismo y republicanismo federal. Barcelona.

ABSTRACT: The aim of the present study is the description of the activity and organisation of the revolutionaries in Barcelona in the period preceding the victory of the Spanish Democratic Revolution of 1868. The activities of those opposition groups, and the clandestine revolutionary Committee existing from 1867, are studied through the analysis of $A$. Feliu Codina's memoirs. The outbreak of the revolution in Barcelona, where the committees were mainly neither republicans nor federalists, enbanced the diffusion of the federal republicanism and transformed an initial pronunciamiento into a true democratic revolution, Barcelona becoming the pioneer of the Spanish federal republicanism.

KEY WORDS: Revolution of 1868. Revolutionary organizations. Federal republicanism. Barcelona.

* Agradezco al Dr. Pere Gabriel, al Dr. Antoni Saumell, a la Dra. Anna Puigdellívol, a la Dra. Marició Janué y a Jaume Claret la lectura crítica de este artículo, aunque los errores únicamente son atribuibles al autor.

Hispania, LXIV/2, núm. 217 (2004) 689-710 


\section{INTRODUCCIÓN}

Este artículo, centrado en la ciudad de Barcelona, pretende ampliar nuestros conocimientos sobre el movimiento juntista de 1867-1868, gracias a los testimonios de quienes participaron directa o indirectamente en los hechos estudiados. De especial utilidad nos han sido las memorias del periodista y dirigente del republicanismo federal barcelonés Antoni Feliu y Codina, ya que nos han aportado nuevos datos sobre la preparación y organización de los revolucionarios barceloneses en el período previo a la revolución de 1868 . Sus memorias son prácticamente inéditas porque únicamente fueron publicadas en la prensa entre 1916 y 1917. A su vez, los recuerdos de Feliu son complementarios con los de personajes tan diversos como Conrad Roure, Joan Garriga y Massó, y Artur Masriera. El primero era un reputado abogado barcelonés, autor teatral de la Renaixença y dirigente del republicanismo federal de la capital catalana. El segundo fue un dirigente del Partido Liberal y posteriormente de la Lliga Regionalista. El tercero era miembro de una acaudalada familia de joyeros, ideológicamente muy conservador y colaborador habitual de la prensa barcelonesa, durante el primer tercio del siglo xx. Estos recuerdos nos permiten plantear cómo se impulsó la revolución de 1868, desde el interior de España, a través de la organización de centros revolucionarios y del movimiento juntista, por parte de una nueva generación de políticos, mayoritariamente de orígenes burgueses, pero influidos por ideas democráticas, regeneradoras, modernizadoras y europeístas.

La última revolución liberal burguesa española acabó con el reinado de Isabel II y representó un importante cambio político, aunque en el ámbito social enfrentó a unas elites políticas mayoritariamente burguesas en lucha por intentar imponer proyectos políticos e ideológicos incompatibles. Esta revolución, también conocida como la Gloriosa, ha sido definida como democrática y equiparada con la europea de 1848, aunque la participación popular, en la revolución española, fue relativamente escasa y la renovación de las elites políticas (entendidas como grupos sociales informales de acceso limitado, relacionadas con el poder político y los principales centros de decisión) quedó limitada a algunas instituciones controladas por los republicanos, en los ámbitos municipal y provincial ${ }^{1}$.

1 Para una visión sintética de los antecedentes y de las causas de la revolución véase MOLINER PRADA, A.: Revolución burguesa y movimiento juntero en España, Lleida, Milenio, 1997, pp. 299-304. En cambio, FUENTE MONGE, G. de la: Los revolucionarios de 1868. Elites y poder en la España liberal, Madrid, Marcial Pons, 2000, es muy crítico con la visión de la revolución de 1868 como una revolución burguesa, democrática, popular y de orientación federalista, postura que se refleja en las páginas 243-246. Este autor reafirma su punto de vista en FUENTE MONGE, G. de la: «Actores y causas de la revolución de 1868", a: SERRANO GARCÍA, R: España, 1868-1874. Nuevos enfoques sobre el sexenio democrático, Valladolid, 2002, pp. 31-57, especialmente en la última de estas páginas. En cambio una perspectiva diferente en PIQUERAS ARENAS, J.A.: «La cuestión cubana, de la revolución gloriosa a la restauración», en SERRANO GARCíA, R: España, 1868-1874. Nuevos enfoques sobre el sexenio demo-

Hispania, LXIV/2, núm. 217 (2004) 689-710 
Para comprender la situación en que se encontraba la ciudad de Barcelona en el periodo previo a la revolución democrática de 1868 , se ha de tener en cuenta la crisis del régimen isabelino. En un período relativamente breve, Isabel II pasó de ser una reina con amplio apoyo popular a ser detestada por la mayor parte de la sociedad española. Esta evolución resulta más comprensible si tenemos en cuenta la situación de crisis política (con pronunciamientos desde $1865)^{2}$, recesión económica (desplome de las exportaciones en 1865 , de la bolsa

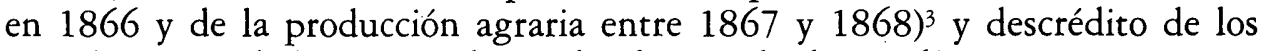
partidos que se habían turnado en el gobierno desde $1856^{4}$. A su vez, una parte de la intelectualidad española impulsaba una opinión pública antiborbónica.

crático, Valladolid, 2002, pp. 159-164. Sobre el concepto de elite y la evolución de las elites profesionales y económicas en el republicanismo español véase GABRIEL, P.: «Elite y República. Sobre las elites profesionales y económicas en el republicanismo español del siglo XIX», Historia Contemporánea (Universidad del País Basco) 23, 2001, pp. 509-542.

2 Olivar Bertrand, R.: Así Cayó Isabel II, Barcelona, Destino, 1955, pp. 116-134. Olivar Bertrand, R.: Prim, Madrid, Tebas, 1975, pp. 370-381. Eiras Roel A.: El Partido Demócrata Español (1849-1868), Rialp, Madrid, 1961, pp. 270-293. DURAN, N.: La Unión liberal y la modernización de España. Una convicencia frustrada, 1854-1868, Madrid, Akal, 1979, pp. 281-294. HEADRICK, D.: Ejército y política (1866-1898), Tecnos, Madrid: 1981, pp. 148-149, asegura que el observador francés Ch. De Mazade-Percin consideraba que los progresistas «siguen creyendo en la insurrección militat, siendo esto quizás en lo único que creen de verdad». Sobre el Partido Progresista y Prim es interesante la aportación de PIQUeras, J.A. Y SeBASTIÀ, E.: Agiotistas, negreros y partisanos, Alfons el Magnànim, Valencia, 1991, pp. 97-110, 118-122 y 182-184. Uno de los más recientes estudios sobre el Partido Progresista es el de Vilches García J.: Progreso y libertad: el Partido Progresista en la revolución liberal española, Alianza, Madrid, 2001, pp. 59-65.

3 Para una aproximación a la situación de la economía española en el período anterior a la revolución los libros ya clásicos de SÁNCHEZ-ALBORNOZ, N.: España bace un siglo: una economía dual, Península, Barcelona, 1968, pp. 148-165 y «El trasfondo económico de la revolución», en LiDA, C. Y E Zavala, I. (Comps.): La Revolución de 1868, Nueva York, Las Americas Publishing, 1970, pp. 64-79. Tortella, G.: Los orígenes del capitalismo en España, Tecnos, Madrid, 1982, pp. 292-298. FONTANA, J.: «Cambio económico y crisis política. Reflexiones sobre las causas de la revolución de 1868», Cambio económico y actitudes políticas en la España del siglo XIX, Ariel, Barcelona, 1981, pp. 99145. También es interesante la aportación de PiQueras, J.A. Y SEbASTIÀ, E.: Agiotistas, negreros y partisanos, op. cit., pp. 36-60.

4 La situación política queda reflejada en los recuerdos de los protagonistas MASRIERA, A.: Barcelona Isabelina y Revolucionaria, Políglota, Barcelona: 1933, pp. 130-150 i 187-197, o en PI Y MARGAll. F. y PI Y ARsUAGA, F.: Historia de España en el siglo XIX, Vol. IV, Barcelona, Miguel Seguí, 1902. Sobre la Unión Liberal nos ofrecen una visión de conjunto DURAN, N.: La Unión liberal, op. cit., pp. 277-338, y MARTínEZ GALLEGO, F.A.: Conservar progresando: la Unión Liberal, 1856-1868, Valencia, Uned, 2001, pp. 234-244. La crisis política del período isabelino y especialmente del Partido Moderado en PIQUeras, J.A. Y Sebastià, E.: Agiotistas, negreros, op. cit., pp. 145-161. Una visión global del período en Cataluña puede encontrarse en RIQUER, B. de: «La vida política catalana, 1856-1898», Catalunya $i$ Espanya al segle XIX, Columna, Barcelona: 1987, pp. 19-56 y en FONTANA, J.: «La fi de l'Antic Règim i la industrialització (1787-1868)», Història de Catalunya, Vol. v, Barcelona, Ed. 62, 1988, pp. 330-353 y de España en ESDAILE, $\mathrm{CH}_{\text {.: }}$ La quiebra del liberalismo, Barcelona, Crítica, 2000, pp. 123-126. 
Finalmente, en el período final de su reinado Isabel II aceptaba la limitación de las libertades públicas defendida por los moderados y era partidaria del misticismo dogmático de su confesor, el padre Claret. En cambio, era ampliamente conocido que no aplicaba la moral católica a su vida sentimentals.

La preferencia de la reina por el Partido Moderado se puso claramente de manifiesto en 1865 , después que los moderados presentasen un proyecto de ley para aprobar una contribución extraordinaria sobre la propiedad y la industria que les permitiese hacer frente al déficit presupuestario que comprometía la estabilidad del gobierno. La propuesta de nuevo gravamen generó una gran repulsa social, y amenazaba con acentuar la crisis económica en que se hallaba inmersa España. Ante esta situación, la reina propuso desamortizar y vender una parte del Patrimonio Real para pagar el déficit. El gobierno pudo retirar su impopular proyecto de nuevo impuesto y quiso compensar la supuesta generosidad de Isabel II acordando que ésta se quedase con el $25 \%$ de la venta, como presupuesto de la Casa Real, y creando un caudal privado del monarca con sustanciales ventajas patrimoniales. Narváez presentó la decisión de la reina como un «rasgo» de generosidad con el pueblo español. En cambio, Castelar, en un artículo que tituló El Rasgo, negó la generosidad de la reina, ya que su objetivo era salvar al gobierno con unos bienes que, en realidad, eran del Estado. Por tanto, «el rasgo del patrimonio no ha sido más que un rasgo de atrevimiento contra las leyes» ${ }^{6}$.

5 Algunos biógrafos de Isabel II, claramente favorables a la monarca, han justificado plenamente que la reina tuviese «favoritos» como LIORCA, C.: Isabel II y su tiempo, Alcoy, Marfil, 1950, pp. 175-176, o Luz, P. De: Isabel II. Reina de España, Juventud, Barcelona, 1962, p. 188, aunque éste asegura que las «libidinosas veleidades» de la reina, en expresión de González Bravo, habrían Ilevado al fin traumático de su reinado. COMELLAS, J.L.: Isabel II. Una reina y un reinado, Barcelona, Ariel, 1999, p. 68, afirma que la moralidad, poco convencional para el período, de Isabel II estaría motivada por el hecho que, durante el trienio progresista (1840-1843), «no fue educada como una reina [...] cuyas consecuencias se echarían a ver muy pronto». En cambio, sorprende que el mismo Comellas, pp. 116-129, no achaque la conducta sexual de la reina al hecho que la regente María Cristina, los moderados, la Santa Sede y la mayor parte de los monárquicos la presionaron, entre 1845 y 1846, para que se casara con uno de sus primos, en un intento de acabar las disputas dinásticas con los carlistas, aunque Francisco de Asís era de «formas amaneradas, o si se quiere poco viriles [...] no era el esposo ideal para una mujer llena de vitalidad y pasión como Isabel II». Los rumores sobre la vida sexual de la reina quedaron reflejados en los dibujos de BÉCQUER V. y BÉCQUER G.A.: Sem. Los Borbones en pelota, edición a cargo de PAGEARD, R., FONTANELLA, L. y CABRA LOREDO, M.D., El Museo Universal, Madrid, 1991, pp. 7-17 i 213-388. Para una aproximación a la política en el reinado d'Isabel II es aconsejable el trabajo colectivo que coordina BURDIEL, I. (ed.), «La política en el reinado de Isabel II», Ayer, (Marcial Pons) 29, 1998, pp. 11-228.

6 La generosidad de la reina es defendida por LloRCA, C.: Isabel II, op. cit., p. 163. Una versión crítica del reinado de Isabel II puede hallarse en OLIVAR BERTRAND, R.: Así Cayó Isabel II, op. cit., pp. 141-142, mientras que COMELlAS, J. L.: Isabel II, op. cit., pp. 299-300, está más cerca de la interpretación de la primera que de la del segundo. El artículo de Castelar lo reproduce PI Y MARGALL, F.: Historia de España, op. cit., pp. 330-334. También son interesantes las aportaciones de EIRAS Roel: El Partido Demócrata, op. cit., p. 299; CASTRO Alfín, D.: «Unidos en la adversidad, 
El gobierno conservador reaccionó ordenando la destitución de Castelar de su cátedra en la Universidad de Madrid. Esta decisión generó la protesta de los estudiantes universitarios madrileños, que fueron drásticamente reprimidos, durante la noche de San Daniel. Hubo entre nueve y dieciséis víctimas mortales, ciento noventa y tres heridos registrados y unos doscientos detenidos ${ }^{7}$. La represión gubernamental aumentó la crispación política (en junio tuvo lugar el pronunciamiento de Prim en Valencia) ${ }^{8}$ y social, indignando a la mayor parte de la población española.

El malestar político y social se concretó en un nuevo gobierno de los unionistas de O'Donnell y en nuevos pronunciamientos dirigidos por los progresistas (el de oficiales en Villarejo y la insurrección de los cuarteles de San Gil en Madrid) cada vez más duramente reprimidos. La represión política dañó seriamente la imagen de la reina, dado que circuló el rumor de que el gobierno de O’Donnell había caído en desgracia al no ordenar la ejecución de todos los detenidos por participar en la rebelión madrileña, aunque sobrepasaban el millar, y haber limitado las ejecuciones a sesenta y seis rebeldes. Esta explicación de los hechos no es aceptada por todos los estudiosos del período, que niegan la supuesta crueldad de Isabel II, pero aceptan que las medidas drásticas de represión eran impulsadas por el círculo íntimo de la reina?

unidos en la discordia: el Partido Demócrata, 1849-1868», en TOwNSON, N. (ED.): El republicanismo en España (1830-1977), Alianza, Madrid, 1994, pp. 82-83, y especialmente el detallado estudio sobre la relación entre el Patrimonio Real, el de la Corona y el caudal privado de la reina en PIQUERAS, J.A. y SEBASTIÀ, E.: Agiotistas, negreros y partisanos, op. cit., pp. 61-84 y 87-95. También es interesante el estudio de VILCHes García, J.: Emilio Castelar. La Patria y la República, Biblioteca Nueva, Madrid, 2001, pp. 53-66.

7 F. PI y MARGALl: Historia de España, op. cit., pp. 319-341. Roure, C.: Recuerdos de mi larga vida, vol. III, Barcelona, Biblioteca de El Diluvio, 1927, pp. 63-78; FelIU I CodINA, A.: El Diluvio, $17,19,21,24,24$ y 26 de julio de 1916, 7, 9, 11, 14, 16, 18, 21, 23, 25, 28 y 30 de agosto de 1916, 7, 11, 15, 18 de septiembre de 1916; MASRIERA, A.: Barcelona Isabelina y Revolucionaria, op. cit., pp. 55-98. Olivar Berrrand, R.: Así cayó Isabel II, op. cit., pp. 143-145. Eiras Roel, A.: El Partido Demócrata, op. cit., pp. 300-304. RuPÉREZ, P.: La cuestión universitaria y la noche de San Daniel, Edicusa, Madrid, 1975, pp. 153-217. DuRAN, N.: La Unión liberal, op. cit., p. 295. PIQueras, J.A. y SeBASTİ̀, E.: Agiotistas, negreros y partisanos, op. cit., pp. 82-86, afirman que la «noche de San Daniel» constituyeron un movimiento espontáneo de los republicanos madrileños. Sin embargo, COMELLAS, J.L.: Isabel II, op..cit., pp. 300-301, desde una óptica revisionista asegura que la violencia fue promovida por «la actitud más violenta de los barrios bajos, movidas por los agitadores de turno». En cambio, VILCHES GARCía, J.: Emilio Castelar, op. cit., pp. 66-70, argumenta que seguramente a la manifestación se sumaron agitadores, pero la represión fue desproporcionada.

8 PiQueras, J.A., y Sebastià, E.: Agiotistas, negreros, op. cit., pp. 134-143.

9 LlorCA, C.: Isabel II y su tiempo, op. cit., p. 168, niega que Isabel II exigiese la ejecución de todos los soldados sublevados. Comparten este criterio DE LUZ, P.: Isabel II, op. cit., p: 213. DURAN, N.: La Unión liberal, op. cit., Pp. 323-327 y COMELLAS, J. L.: Isabel II, op. cit., p. 308. En cambio, defienden un punto de vista radicalmente diferente en PI Y MARGALL, F.: Historia de Espa$\tilde{n} a$, op. cit., pp. 362-370. MiQuel I Vergés, J.M.: El general Prim. En España y en México, Hermes, México, 1949, pp. 332-355, y Olivar Bertrand, R.: Así cayó Isabel II, op. cit., p. 156. 
En estas circunstancias, Isabel II confió por última vez el gobierno a Narváez que, fiel a sus principios, impulsó un duro período de represión política (aunque suspendió las ejecuciones sumarias) y de limitación de las libertades civiles e ideológicas. El incremento de la represión implicó la radicalización de los opositores, desde los demócratas a los centristas de la Unión Liberal. Sin embargo, O'Donnell, a pesar de haber sido apartado del gobierno, se opuso sistemáticamente a rebelarse contra la reina. Se mantuvo fiel a sus principios hasta su muerte el 5 de noviembre de 1867, a causa de una indigestión de ostras, según las primeras versiones, mientras que sus biógrafos aseguran que murió de tifus, aunque circularon rumores de que había sido asesinado. Fue substituido en la jefatura de la Unión Liberal por Francisco Serrano, un general menos dispuesto a sostener al régimen de Isabel $\mathrm{II}^{10}$. Tras la muerte de Narváez el 23 de abril de 1868, el gobierno del Partido Moderado pasó a estar controlado por González Bravo ${ }^{11}$. Éste se mantenía en el poder únicamente por el apoyo de la reina, de su partido y de una parte del ejército.

Durante los años previos a la revolución de 1868, las conspiraciones opositoras contra los gobiernos conservadores se generalizaron y Barcelona no fue una excepción. En la ciudad todos hablaban del «golpe», es decir, de la hecatombe que cambiaría «todo lo existente», con la sustitución del gobierno de los moderados por la coalición que agrupaba a la mayor parte de las fuerzas políticas liberales españolas. Los partidarios del «golpe» afirmaban que éste acabaría con el predominio de los gobiernos conservadores e incluso con el reinado de Isabel II, iniciando el proceso de regeneración modernizadora que necesitaba España. En cambio, los conservadores veían el «golpe» como una fatalidad inevitable ${ }^{12}$.

10 Encontrarán más información en PI Y MARGALL, F.: Historia de España, op. cit., p. 394; FELIU I CoDINA, A.: «Fallecimiento del general O’Donnell», El Diluvio, 13 de octubre de 1916; OlIvar Bertrand, R.: Así cayó Isabel II, op. cit., p. 183; EIras Roel, A.: El Partido Demócrata, op. cit., pp. 343-344. DURAN, N.: La Unión liberal, op. cit., pp. 331-337; HEADRICK, D.: Ejército y política, op. cit., pp. 150-154. Para una información más amplia del último gobierno de Narváez véase PIQUERAS, J.A. Y SEBASTIÀ, E.: Agiotistas, negreros, op. cit., pp. 184-189, 301-337 y sobre la muerte de O'Donnell las pp. 359-360, y Vilches García: Progreso y libertad, op. cit., pp. 69-71.

11 Pi i Margall, F.: Historia de España, op. cit., pp. 396-397. Feliu i CodinA, A.: «Enfermedad delirio y muerte de Narváez», El Diluvio, 15 de octubre de 1916.

12 García Ruiz, E.: La Revolución en España, Imp. Ch. Lahure, París 1867. Pi y Margall F.: Historia de España, op. cit., pp. 397-403. ROURE, C.: Recuerdos de mi larga vida, op. cit., 1927, pp. 63-78; MASRIERA, A.: Barcelona Isabelina y Revolucionaria, op. cit., pp. 55-98; MESTRES, A.: Història viscuda, Barcelona, Salvador Bonavia, 1929, pp. 30-35; HENNESSY, C.A.M.: La República federal en España. Pi y Margall y el movimiento republicano federal 1868-1874, Aguilar, Madrid: 1962, pp. 34-56. FontanA, J.: Història de Catalunya, op. cit., pp. 336-338. Piqueras J.A. y Sebastià E.: Agiotistas, negreros, op. cit., pp. 180, 337 y 361. MOLINER PRADA, A.: Revolución burguesa, op. cit., p. 302, y ESDAILE, CH.: La quiebra del liberalismo, op. cit., p. 126.

Hispania, LXIV/2, núm. 217 (2004) 689-710 


\section{Los PREPARATIVOS DEL «GOLPE» EN BARCELONA. El GRUPO DEL CAFÉ SUIZO}

La oposición - progresistas y demócratas - se había unido en el pacto de Ostende en agosto de 1866, alianza que con dificultades mantuvieron en el acuerdo de Bruselas en noviembre de 1867, y a la que se adhirieron los unionistas después de la muerte de O'Donnell. El acuerdo entre los dirigentes de las principales formaciones políticas en la oposición implicaba la voluntad de llegar al poder por la vía insurreccional, a través del tradicional pronunciamiento, entendido como un mecanismo para forzar el cambio político sin alterar la estructura institucional española. La oposición se organizaba en dos frentes complementarios: uno, el de los exiliados, que unía a los principales dirigentes de los opositores, tanto militares - los generales Prim o Serranocomo civiles - Ruiz Zorrilla o Castelar- entre otros ${ }^{13}$; el segundo, integrado y dirigido mayoritariamente por civiles estaba vinculado, como ya explicaba Bozal, a la aparición en 1867 de juntas revolucionarias clandestinas en Madrid, Barcelona y Zaragoza que promovían el ambiente revolucionario en el interior, para que triunfase la rebelión que se fraguaba en el exilio ${ }^{14}$.

Sin embargo, conocíamos muy pocos detalles de la actividad de estas Juntas clandestinas y centradas en la de Madrid, a partir de las informaciones que Lara publicó en 1868. Lo único que conocíamos de la Junta clandestina de Barcelona eran dos manifiestos: El primero fue publicado en enero de 1868, reclamando la soberanía nacional. El segundo salió a la luz el 20 de septiembre del mismo año, incitando a la revolución. Aunque no deben confundirse las juntas clandestinas - en su mayor parte partidistas, a la vez que dedicadas a buscar y coordinar los medios para llevar a cabo la revolución-, con las juntas revolucionarias de gobierno que se instalaron en el poder a finales de septiembre de $1868^{15}$. Pero las memorias de Antoni Feliu nos permiten afirmar que la Junta revolucionaria clandestina barcelonesa dirigía y controlaba a los revolucionarios de la capital catalana ${ }^{16}$.

13 La actividad política de los exiliados ha sido explicada por ÁlVAREZ VilLAMIL, V. Y LIOPIS, R: Cartas de Conspiradores. La Revolución de septiembre, Espasa Calpe, Madrid, 1929. EIRAS ROEL, A.: El Partido Demócrata Español, op. cit., pp. 325-360. HenNEssy, C.A.M.: La República federal en España, op. cit., pp. 40-43. Olivar BerTRAND, R. Así cayó Isabel II, op. cit., pp. 156-160 y 201-202, y del mismo autor Prim, op. cit., pp. 414-426. EsteBAN NAVARRO, M.Á.: «De la Esperanza a la frustración», en N. TOWNSON (ed.): El republicanismo, op. cit., pp. 90-91. VILCHES GARCÍA, J.: Progreso y libertad, op. cit., pp. 71-72 y del mismo autor Emilio Castelar, op. cit., pp. 79-83. Sobre la adhesión de la Unión Liberal a la conspiración véase PIQUERAS, J.A. Y SEBASTIÀ, E.: Agiotistas, negreros, op. cit., pp. 361-366.

14 BOZAL, V.: Juntas Revolucionarias. Manifiestos y proclamas, Edicusa, 1968, pp. 14-15 y 31-33. MOLINER PRADA, A.: Revolución burguesa, op. cit., p. 304, y FUENTE MONGE, G. de la: Los revolucionarios de, op. cit., pp. 67-74.

15 LARA, D. M. M DE: El Cronista de la Revolución, Imp. Verdeguer, Barcelona: 1869. BOZAL, V.: Juntas Revolucionarias, op. cit., pp. 32-36 y 51-66. MOLINER PRADA, A.: Revolución burguesa, op cit., pp. 304 y 314, o FUENTE MONGE, G. de la: Los revolucionarios de, op. cit. p. 67.

16 PICH, J.: Valentí Almirall i Llozer (1841-1904) i la gènesi del catalanisme polític, Tesis doctoral dirigida por TERMES, J., IUHJVV-UPF, Barcelona, 1999, pp. 107-160, i FELIU I CODINA: «Memo- 
La situación de Madrid, en el período prerrevolucionario, ha sido extrapolada al resto de ciudades con juntas revolucionarias clandestinas. Fuente Monge afirma que los «centros revolucionarios partidistas habían proliferado por todas las ciudades, pero fue en la capital del estado donde abundaron como en ningún otro sitio", a mediados de 1868. Nos relata cómo en los centros clandestinos típicos predominaban las relaciones personales y una estructura formal mínima. De hecho, la diversidad de sus tramas dificulta la valoración del papel desempeñado por las juntas clandestinas, como verdaderos núcleos revolucionarios. No obstante, los generales rebeldes encontraron, en estas «mallas de conspiración», los resortes necesarios para el buen término del pronunciamiento iniciado en Cádiz. Las memorias de Feliu nos permiten conocer su funcionamiento, organización y actividades en Barcelona. Allí se habían organizado, desde 1867, unos catorce "centros revolucionarios» y una Junta clandestina que, posteriormente, impulsó la constitución de la Junta revolucionaria provisional de Barcelona ${ }^{17}$.

En 1867, Antoni Feliu y Codina era integrante del «centro revolucionario» que se reunía en el Café Suizo de Barcelona, concretamente en la mesa catorce, donde comentaban las últimas noticias de los opositores al régimen isabelino que actuaban tanto dentro como fuera de España. Además de Feliu, la frecuentaban su hermano, el literato y político progresista Josep Feliu, Joan Tutau (posteriormente ministro de Hacienda durante la Primera República), Valentí Almirall (dirigente del federalismo intransigente barcelonés durante el Sexenio y la Primera República, y, más tarde, impulsor de la politización del movimiento catalanista), Gonçal Serraclara (diputado del Partido Republicano Democrático Federal en las Cortes Constituyentes de 1869), Manuel de Lasarte (periodista con una amplia trayectoria en la prensa barcelonesa de la segunda mitad del s. xix; fundador y director de El Diluvio), Innocenci López Bernagosi (el propietario de la Librería Española, una de las principales editoriales de Barcelona), los hermanos Jaume, Baldomer y Conrad Roure (los dos primeros eran progresistas, mientras el tercero era republicano federal moderado), Jaume Garriga (progresista, después de la revolución, tuvo una larga trayectoria como fiscal y magistrado), Josep Lluís Pellicer y Tomàs Padró (fueron reputados dibujantes y políticamente militaron en el republicanismo federal), entre otros. Este centro revolucionario estaba encabezado por el acaudalado comerciante Cirili Montserrat, que confiaba en el triunfo de la revolución democrática para modernizar y regenerar España. Las fuerzas de seguridad del estado decidieron acabar con la peculiar «tertulia» cerrando el local, pero la imposición policial generó un movimiento solidario que consiguió la reapertura del café18.

\footnotetext{
rias de un veterano de la República», El Diluvio, Barcelona, publicadas entre el junio de 1916 y septiembre de 1917.

17 FUENTE MONGE, G. de la: Los revolucionarios de 1868, op. cit., pp. 69-73. Feliu I CodinA, A.: El Diluvio, 8 y 15 de octubre de 1916.

18 Feliu i Codina, A.: «El café Suizo», El Diluvio, 27 de septiembre de 1916 y 2 de octubre de 1916.
}

Hispania, LXIV/2, núm. 217 (2004) 689-710 
Las actividades del grupo iban desde la circulación y divulgación de información a la propaganda revolucionaria, de la ayuda a los represaliados políticos a lo que requiriesen los opositores al régimen isabelino. Así pues, a mediados de agosto de 1867, cuando progresistas y demócratas impulsaron un nuevo pronunciamiento, los miembros de la «tertulia» del Café Suizo intentaron ayudar a los rebeldes en la medida de sus posibilidades. Antoni Feliu, Innocenci López, Baldomer Roure, Coll, Narcís Monturiol (el inventor del Ictineo, uno de los primeros sumergibles), y el socio de éste, Borràs, acordaron colocar algunos artefactos explosivos de baja potencia (Feliu los describía como petardos) en diferentes puntos de la ciudad con la finalidad de causar alarma social e impedir así que las tropas acuarteladas en Barcelona se sumasen a la persecución de las columnas de los insurrectos. De hecho, el plan cumplió sus objetivos, ya que la mayor parte de la guarnición de la capital catalana se quedó en sus cuarteles y posibilitó que la columna encabezada por Baldrich fuese la última en ser derrotada por las tropas gubernamentales ${ }^{19}$.

El fracaso del pronunciamiento de 1867 implicó un aumento de la represión sobre la oposición política en general y los demócratas republicanos en particular. El músico y dirigente demócrata republicano catalán, Josep Anselm Clavé fue encerrado en la cárcel del Saladero de Madrid; Conrad Roure recordaba que «igual o peor suerte todavía [que Clavé] les habría cabido a Joarizti y Antonio Altadill si Almirall y yo [los dos eran miembros de la «tertulia» del Café Suizo] no hubiésemos procurado por ellos buscándoles pasaje en un buque francés y embarcándoles ocultamente en él.» Los dos jóvenes abogados barceloneses acompañaron a los dos dirigentes demócratas al barco. Durante el trayecto en barca, Altadill se mareó y les decía que «m'agarren o que'm maten; tant me fa! Però tornau-me a terra! [Me pillen o que me maten; itanto me da! Pero idevolvedme a tierra!].» Evidentemente no le hicieron caso ${ }^{20}$. La represión gubernamental, entre 1866 y 1868, implicó la detención, el exilio y, en algunos casos, la muerte de algunos de los más significados dirigentes de la oposición política catalana, como la de Vicenç Martí Torres, «el Noi de la Barraqueta», asesinado por un guardia civil en 1866, o la de Albert Columbrí, muerto durante su destierro en Sevilla ${ }^{21}$.

19 Para lo sucedido en el pronunciamiento de 1867 García RuIZ, E.: La Revolución en España, op. cit., pp. 55-123. Feliu I CoDinA, A.: El Diluvio, 2 y 4 de septiembre de 1916, 4, 6, 9, 11, 13, $15,16,18,20,23$ y 25 de octubre de 1916. ROURE, C.: Recuerdos de mi larga vida, op. cit., 1927, pp. 85-88. MASRIERA, A.: Barcelona Isabelina y Revolucionaria, op. cit., pp. 100-103. MIQUEL I VeRGÉs: El general Prim, op. cit., pp. 362-369. EIRAs RoEL, A.: El Partido Demócrata Español, op. cit., pp. 340-343. HENNESSY, C.A.M.: La República federal en España, op. cit., pp. 43-44. OlivaR BERTRAND, R.: Así cayó Isabel II, op. cit., pp. 165-174, y del mismo autor Prim, op. cit., pp. 426-440, y PIQUERAS J.A. Y SEBASTIÀ E.: Agiotistas, negreros y partisanos, op. cit., pp. 339-348.

20 ROURE, C.: Recuerdos de mi larga vida, op. cit., p. 88.

21 Feliu I CodinA, A.: «El Noi de la Barraqueta», 19 de julio de 1916, 27 y 29 de diciembre de 1916. Mestre i CAMPI, J. (dir.): Diccionari d'bistòria de Catalunya, Barcelona, Edicions 62, p. 662. 
El incremento de la represión se manifestó incluso en la censura de un periódico ideológicamente tan conservador como El Diario de Barcelona. La policía redobló sus esfuerzos para detener a los contrarios al régimen y se incrementó el número de exiliados políticos españoles en Francia, en Inglaterra, en Bélgica y en Suiza, mientras que «en España todo el mundo se preguntaba: ¿Cuándo vuelve a estallar la revolución? ¿Cuándo cae el trono de Isabel II? ¿Cuándo se derrumba lo existente?». Feliu recordaba que los partidarios de la revolución «estábamos en Barcelona con el alma pendiente de un hilo», porque los encarcelamientos por delitos políticos implicaban deportaciones a islas como Fernando Póo o las Carolinas. Aun así, los núcleos contrarios al régimen isabelino se mantuvieron activos y «sabíamos cuanto ocurría en el extranjero y las instrucciones que se comunicaban, no tan sólo a cuantos conspiraban fuera de España, que eran muchos, sino a cuantos hacíamos lo propio en el interior» ${ }^{22}$.

Los opositores barceloneses al régimen isabelino, a pesar de la represión policial, continuaban reuniéndose en los Cafés Suizo y del Correo (éste era el punto de encuentro de los republicanos más belicosos), en la Librería Española del demócrata republicano Inocencio López y en la de Eudald Puig, en las farmacias de los doctores Codina y Genové, en la pasamanería del progresista Jaume Aymar, en la quincallería de los demócratas republicanos Tutau y Comas, en la fábrica de chocolates de Bordas, en la relojería de Frederic Soler, en los elegantes círculos Ecuestre y del Liceo (donde se reunían los partidarios de la revolución de tendencia conservadora), en la confitería de la Gloria (el punto de encuentro de los principales dirigentes progresistas barceloneses), y en una modesta tienda de la plaza de las Beatas (donde se reunían los obreros partidarios de hacer caer «lo.existente»). Además, cada domingo, en la fonda del Pujol del Coll, Feliu y Virnadell comían con sargentos y oficiales de la guarnición de Barcelona dispuestos a rebelarse contra el gobierno. En definitiva, Feliu aseguraba que «todo marchaba como una seda. Todo iba a pedir de boca. La revolución estaba en el ambiente y era inevitable» ${ }^{23}$.

Los revolucionarios barceloneses recibían libros y artículos que habían sido prohibidos o censurados por el gobierno, siendo objeto de sesiones de lectura clandestina. En estos ambientes, a mediados de 1868, el autor más leído era Eugenio García Ruiz, y circulaban artículos como «La última palabra» o «iMisterios!.» El primero, publicado por el diario próximo a los progresistas La Nueva Iberia, defendía la alianza de progresistas y unionistas, mientras que el se-

FOnTANA, J.: Història de Catalunya, op. cit., pp. 297, 321-322 i 342-344 y TERMES, J.: «De la Revolució de Setembre a la Guerra Civil (1868-1939)», Història de Catalunya, Vol. vI, Barcelona, Edicions 62, pp. 48 y 70.

22 Feliu i Codina, A.: El Diluvio, Barcelona, 8, 10 y 13 de octubre de 1916. Piqueras, J.A. Y SEBASTIÀ, E.: Agiotistas, negreros, op. cit., pp. 188-189.

23 Feliu i CodinA, A.: El Diluvio, 8 y 15 de octubre de 1916; Roure, C.: Recuerdos de mi larga vida, op. cit., pp. 257-258; MESTRES, A.: Història viscuda, Barcelona, Salvador Bonavia, 1929, pp. 30-35, y MASRIERA, A.: Barcelona Isabelina y Revolucionaria, op. cit., pp. 60-65 y 109. 
gundo provenía de El Diario Español, uno de los periódicos de referencia de los conservadores españoles, era atribuido al dirigente de la Unión Liberal Lorenzana. Este artículo, ségún Masriera, era «una de tantas paletadas de barro del arroyo lanzada a la frente de la casa reinante de Borbón, con todo el cinismo y cobardía que prestan la certeza de la impunidad [el artículo atribuido a Lorenzana, afirmaba que Isabel II era una nueva Mesalina] dibujaba una serie de semblanzas del rey Don Francisco, de la monja Sor Patricio, del confesor P. Claret, del ministro señor Marfori, del tenor de zarzuela Obregón [...] Solamente aquella mínima parte de personas ecuánimes y de recta conciencia que en todas épocas ha habido en todas las naciones, supo indignarse y despreciar tal modo de atacar un régimen y una dinastía. Pero el pueblo bajuno y de epidermis de jabalí y la llamada masa neutra, corearon aquellos mugidos, injertos de rebuzno, y sonrieron con malicia astuta del que goza viendo en el polvo lo que siempre debió estar en el pedestal.» Sin embargo, en aquellos días de inestabilidad política, el joven Masriera asistía a los actos de lectura de los artículos prohibidos y reconocía que, después de una de aquellas sesiones, se tenía la sensación que el destronamiento de Isabel II sería inmediato ${ }^{24}$.

El jefe del gobierno era el conservador Luís González Bravo que, para intentar acabar con la inestabilidad política, había afirmado: "yo haré ver que también un paisano puede ejercer la dictadura en España.» Sin embargo, la política de confrontación con la oposición desplegada por el nuevo gobierno no tuvo en cuenta que, en aquel período, gobernaba quien tenía el apoyo del ejército y éste, en su mayor parte, estaba bajo el control de generales que a su vez dirigían las principales formaciones políticas españolas. Por tanto, un civil no podía proclamarse dictador en España ${ }^{25}$. En esta coyuntura comenzó el pronunciamiento de Cádiz en septiembre de $1868^{26}$.

24 FELIU I CODINA, A.: «La última palabra», "Una sesión de lectura periodística», El Diluvio, Barcelona, 15, 17 y 20 de octubre de 1916; una visión contrapuesta puede encontrarse en MASRIERA, A.: Barcelona Isabelina, op. cit., pp. 67-69 y 141-142. También son interesantes los datos aportados por PI y Margall, F.: Historia de España, op. cit. p. 323 o Olivar BerTrand, R.: Así cayó Isabel II, op. cit., p. 200.

${ }_{25}$ Feliu I CodinA, A.: ibídem. Roure, C.: Recuerdos de mi larga vida, op. cit., pp. 85-97. Pi y MARGall, F.: Historia de España, op. cit., pp. 404-423. MIQUEl I VeRGÉs, J.M.: El general Prim, op. cit., pp. 373-385. DurAn, N.: La Unión liberal, op. cit., pp. 337-338. HEADRICK, D: Ejército y política, op. cit., pp. 151 y 154-155, y PIQUERAS, J.A. Y SEBASTIÀ, E.: Agiotistas, negreros, op. cit., pp. 360-361 y 366-374.

26 La evolución del pronunciamiento se halla sintetizada en BOZAL, V.: Juntas Revolucionarias, op. cit., pp. 15-25 y 67-83, reproduce los manifiestos de Topete y Prim, así como algunas de las primeras proclamas de las juntas. También es interesante el estudio de HEADRICK, D.: Ejército y política, op. cit., pp. 157-161. 


\section{LOS PREPARATIVOS DE LA REVOLUCIÓN DE 1868 EN BARCELONA}

La mayor parte de los impulsores de la revolución de septiembre intentaban conseguir el poder político y la abdicación de Isabel II. Aunque no querían; en cambio, dejar un margen de maniobra demasiado amplio a los demócratas republicanos, el pronunciamiento iniciado en Cádiz por el almirante Topete se transformó en Barcelona en una revolución democrática. Ésta se concretó en el deseo generalizado de transformaciones profundas del sistema político e institucional español, en la eclosión de una nueva generación de políticos, así como en la génesis y consolidación del movimiento republicano federal. De hecho, la revolución de 1868 no fue únicamente una iniciativa controlada «desde arriba» [por los dirigentes políticos, militares y civiles exilados], ya que no se ha de obviar la actividad de los centros revolucionarios activos en las principales ciudades españolas, «desde abajo.» En los días decisivos de la insurrección, la función de las Juntas Revolucionarias clandestinas, como la de Barcelona, era compleja y arriesgada. Se ocupaban de crear los mecanismos, a través de periódicos o manifiestos, que permitían informar sobre la insurrección contrarrestando los efectos de las noticias difundidas por las autoridades fieles a la reina. A su vez, animaban a la población a ponerse de su parte, pero no de manera espontánea, sino bajo su dirección. Sin la existencia de las juntas, constituidas por los civiles más activos de las elites revolucionarias, el triunfo de los pronunciados habría sido mucho más complicado ${ }^{27}$. De hecho, los avisos de algunos policías y de autoridades que intuían el fin del reinado de Isabel II impidieron las detenciones de algunos de los más significados opositores y de la Junta clandestina barcelonesa.

Aunque los revolucionarios barceloneses esperaron doce días a sumarse a la revolución, la noticia del inicio del pronunciamiento llegó a Barcelona inmediatamente. Posiblemente ésta prudencia estaba motivada por los escarmientos recibidos tras los fracasos de las insurrecciones precedentes ${ }^{28}$. En estas circunstancias, la Junta clandestina de Barcelona frenó los ánimos de los revolucionarios más radicales, mientras esperaba el momento oportuno para sumarse a la revolución. La dirección de los revolucionarios barceloneses tenía como uno de sus primeros objetivos la voluntad de mantener el orden público durante el período revolucionario. Éste interés estaría motivado por la necesidad de evitar que los contrarrevolucionarios se aprovechasen de la situación, aunque lo más

27 BOZAL, V.: Juntas Revolucionarias, op. cit., pp. 29 y 36-37. FONTANA, J.: «Cambio económico y crisis política", op. cit., pp. 127-128, y FUENTE MONGE, G. de la: Los revolucionarios de, op. cit., pp. 74.

28 Feliu i CodinA, A.: El Diluvio, 17 de octubre de 1916, 22 y 27 de noviembre de 1916 y 1 de diciembre de 1916; LARA, D. M. M. DE: El Cronista de la Revolución, op. cit., pp. 5-124; MASRIERA, A.: Barcelona isabelina y revolucionaria, op. cit., pp. 146-147 y 165-174; ALTADILL, A.: La monarquía sin monarca. Grandezas y miserias de la Revolución de setiembre, Eduardo González, Barcelona: 1869, pp. 9-24; TUBINO, F.M.: Historia del Renacimiento literario en Cataluña, Baleares y Valencia, Tello, Madrid, 1880, pp. 427-431, y GARRIGA I MASsó, J.: Memòries d'un liberal catalanista (18711939), Edicions 62, Barcelona, 1987, pp. 38-39.

Hispania, LXIV/2, núm. 217 (2004) 689-710 
probable es que temieran que, si no controlaban a los elementos más radicales, la revolución se transformase en una «bullanga», es decir en una asonada. En consecuencia, organizaron sus propios cuerpos de seguridad para evitar la destrucción o el robo de bienes públicos y privados, las venganzas personales y los ataques al orden social vigente ${ }^{29}$.

A pesar de la censura, los revolucionarios barceloneses estaban muy bien informados de lo que acontecía en Andalucía, ya que tenían acceso a la prensa, tanto de la extranjera como la de Sevilla y Cádiz, a través del servicio de correos. Sin embargo, su principal fuente de información estaba en el servicio de telégrafos. Feliu recordaba que su hermano Josep y su primo Roque y Feliu le informaron del inicio de la revolución cuando «aún no es oficial. En esta Capitanía general y en el Gobierno civil nada saben de ella. En cambio, los telegrafistas de Cádiz y Sevilla, que están en relación con todos los de España, se han encargado de propagarla y divulgarla a espaldas del Gobierno» ${ }^{30}$.

Después de conocer el inicio de la rebelión, Feliu se dirigió a los centros revolucionarios que frecuentaba para informarlos de la noticia. El joven revolucionario se dirigió inicialmente a la librería de Eudald Puig, más tarde a la Española de Innocenci López, posteriormente al Café Suizo y, finalmente, a la relojería de Frederic Soler, el principal impulsor del teatro moderno catalán, donde solían reunirse algunos de sus amigos «tertulianos.» Al llegar a la relojería, ya se encontraban allí su hermano Josep y su primo Roque, vio que Soler estaba entusiasmado y compartían su alborozo Serraclara, Lasarte, Montserrat, Baldomer Roure y Almirall. Éste último habría afirmado que estaba dispuesto «a entregarse en cuerpo y alma a la revolución llevado del noble propósito de contribuir a que se estableciera en España la República democrática federal» ${ }^{31}$.

El 18 de septiembre de 1868, un día después del pronunciamiento de Topete, Almirall se reunía con Feliu y Codina para hablar de la posible creación del Partido Republicano Federal en Barcelona. En esta reunión establecieron las bases para constituir el Club de los Federalistas, el primer club republicano federal de Barcelona y uno de los primeros de España. Esta asociación política fue organizada antes que se constituyese el Partido Republicano Democrático

29 BOZAL, V.: Juntas Revolucionarias, op. cit., p. 37. FONTANA, J.: "Catalunya i la revolució de 1868», L'Avenç, 17 (junio de 1979), pp. 48-61, y también "La fi de l'Antic Règim i la industrialització (1787-1868)», Història de Catalunya, Vol. v, Barcelona, Ed. 62, 1988, pp. 345-350, donde ponía de manifiesto la pasividad de los revolucionarios barceloneses en los días previos al inicio de la revolución de 1868, a partir de los datos que entonces estaban disponibles. PIQUERAS, J.A.: La Revolución Democrática (1868-1874), MṪYSS, Madrid, 1992, pp. 47-48, argumenta que las juntas revolucionarias no cuestionaban la propiedad privada, aun cuando no tenían recursos para no defraudar las expectativas creadas, y FUENTE MONGE, G. de la: Los revolucionarios de, op. cit., p. 107.

30 Feliu i Codina, A.: El Diluvio, Barcelona, 22 y 27 de noviembre de 1916 y 1 de diciembre de 1916. La vinculación de los telegrafistas con los insurrectos es reconocida por PI Y MARGALL, F.: Historia de España, op. cit, p. 428 o FUENTE MONGE, G. de la: Los revolucionarios de 1868, op. cit., p. 81.

31 Feliu i Codina, A.: El Diluvio, 22 de noviembre de 1916. 
Federal (PRDF), partido político constituido en los inicios del Sexenio democrático, a partir de la tendencia mayoritaria del antiguo Partido Democrático. El PRDF agrupó la mayor parte de las tendencias democráticas, republicanas y federales españolas hasta la crisis de la Primera República ${ }^{32}$.

Los fundadores del Club de los Federalistas eran una parte de los jóvenes que conspiraban en el Café Suizo y en la trastienda de la relojería de Frederic Soler. La novedad ideológica más remarcable de la nueva generación de dirigentes demócratas republicanos barceloneses era la pretensión de transformar España en una federación similar a la norteamericana o la suiza.

Los jóvenes revolucionarios que se reunían en el Café Suizo, mientras esperaban el inicio de la insurrección en Barcelona, se convencieron de la necesidad de informar a la población de la evolución de la rebelión y, con esta finalidad, impulsaron la publicación de un diario clandestino titulado Boletín Oficial de la Revolución, con el beneplácito de la Junta revolucionaria clandestina. El director de la publicación era Josep Feliu, mientras que la redacción estaba integrada por su hermano Antoni, su primo Roque, y sus amigos Almirall y Serraclara. Por tanto, el director y uno de los redactores, Roque, eran progresistas y los otros tres republicanos federales ${ }^{33}$.

Los redactores del Boletín Oficial de la Revolución habían sido previamente integrantes del movimiento bumorista barcelonés, vinculado a la recuperación cultural catalana impulsada por la «Renaixença», y conocidos despectivamente como «xarons» (bromistas ordinarios y sin gracia). Éstos no olvidaron su faceta bromista y enviaban cada mañana el Boletín al capitán general de Cataluña, Juan de la Pezuela Ceballos conde de Cheste, que respondió con un bando en que les condenaba a muerte en caso de ser detenidos. Masriera alababa la caballerosidad, el valor personal, el carácter, la capacidad de trabajo, la cortesía y la fidelidad a la monarquía del capitán general de Cataluña, pero, desde la perspectiva de los conservadores monárquicos catalanes, tenía el defecto de ser «ipoeta! Y con poetas no se hacen abortar revoluciones» ${ }^{34}$.

El 22 de septiembre de 1868, el grupo que redactaba el Boletín sufrió un gran sobresalto cuando, estando reunidos en la trastienda de la relojería de Soler; se presentó un mozo de escuadra con una orden del conde de Cheste

32 Molas, I (editor y director): Diccionari dels Partits Politics de Catalunya, Barcelona, Enciclopèdia Catalana, 2000, pp. 269-279, PÉREZ RoldÁN, C.: El Partido Republicano Federal 18681874, Madrid, Endymion, 2001 y DuARTE, À.: Història del republicanismo a Catalunya, Lleida-Vic, Pagès ed. i Eumo,.2004, p. 88.

33 Feliu i Codina, A.: El Diluvio, Barcelona, 27 de noviembre de 1916 y 1 de diciembre de 1916. PI y MARGALl, F.: Historia de España, op. cit., p. 428, explican que en Madrid también publicaban un Boletín Revolucionario. BOZAL, V.: Juntas Revolucionarias, op. cit., p. 36, asegura que el Boletín publicado en la capital de España proporcionaba una información bastante exacta de los acontecimientos militares y dictaba normas de comportamiento a la población.

34 F. C. [¿'Feliu I CodinA, A.?]: El Estado Catalán, núm. 69, 21 de septiembre de 1869, p. 1 y del mismo autor El Diluvio, Barcelona, 4 de diciembre de 1916. MASRIERA, A.: Barcelona Isabelina y Revolucionaria, op. cit., pp. 151-156.

Hispania, LXIV/2, núm. 217 (2004) 689-710 
donde se requería al relojero, poeta y autor teatral para que acudiera a la capitanía general. Josep Feliu, amigo, literato y abogado, se prestó a acompañarlo. Juan de la Pezuela los recibió cortésmente, les recordó que él también era un literato y pidió a Soler que tradujese al catalán el manifiesto que había escrito para explicar a las clases populares catalanas el pronunciamiento iniciado en las playas gaditanas, «al cabo de media hora [de traducción] aquel par de revolucionarios [...] hacían entrega al general de aquel famoso documento histórico en el que se pretendía ridículamente excitar el sentimiento regionalista de los catalanes hablándoles de la patria de los Peres y los Jaumes.» El conde de Cheste era consciente de que un documento escrito en catalán coloquial podía ser bien acogido por las clases populares barcelonesas y Soler era la cabeza visible del grupo de escritores que utilizaban lo que en el período llamaban «el català que ara es parla [el catalán que se habla ahora].» Pero, cuando publicaron el manifiesto comenzaron a circular rumores (posiblemente impulsados por el grupo que se reunía en la trastienda de la relojería de Soler) asegurando que su autor era, en realidad, Pitarra, pseudónimo literario de Soler, con lo que se desacreditaba aún más el manifiesto al ser presentado como la obra de un bromista ${ }^{35}$.

La Junta clandestina barcelonesa estaba presidida por T. Fábregas e integrada por los vocales J. Tutau, F. Soler y Matas, J. Garriga, F. de P. Roque y Feliu, R. Mascaró, I. López Bernagosi, B. Lostau, G. Núñez de Arce y F. Pérez Zamora. Los dos últimos eran los representantes que la Unión Liberal había enviado a Barcelona. De los restantes miembros de la Junta, cinco eran progresistas y tres demócratas republicanos. La dirección de los revolucionarios barceloneses se reunía casi diariamente en un piso de Josep Tomàs y Salvany, rico comerciante y amigo de Castelar. De hecho, resulta sorprendente que ni la policía, ni los mozos de escuadra, que tenían el cuartel muy cerca del piso en que se reunía la Junta, no supiesen nada de estas reuniones. La Junta controló a los revolucionarios barceloneses hasta que llegó el momento oportuno de sumarse a la insurrección. Sin embargo, en Barcelona, el pronunciamiento iniciado en Cádiz fue algo más que un cambio de gobierno por la vía militar. En la capital catalana existía el sentimiento que la revolución concluía una etapa histórica e impulsaría una profunda transformación de la estructura políticoinstitucional española ${ }^{36}$.

Durante los días previos a la revolución, la Junta revolucionaria clandestina coordinaba los diferentes centros revolucionarios barceloneses. A su vez, para apaciguar a los más radicales, ordenó la publicación de un manifiesto en favor de la revolución y la organización de una manifestación estudiantil. El manifiesto, publicado el 20 de septiembre, fue redactado por Robert Robert y Antoni Altadill, mientras que López Bernagosi se encargó de la impresión de unos ocho mil ejemplares y Baldomer Lostau de la difusión. La proclama de la Junta

35 Feliu i Codina, A.: El Diluvio, Barcelona, 1 de diciembre de 1916.

36 Feliu i Codina, A.: El Diluvio, 14 de diciembre de 1916. 
revolucionaria barcelonesa defendía la necesidad de derribar el régimen político isabelino, democratizar el sistema político a través de la instauración del sufragio universal y acabar con la confesionalidad católica del estado para consolidar el liberalismo en España. También proponía que se convocasen elecciones a Cortes Constituyentes, tras el triunfo de la revolución ${ }^{37}$.

En cuanto a la manifestación estudiantil, el momento no era el más idóneo para organizarla, no sólo por la posible represión policial, sino porque aún no se había iniciado el curso en la Universidad. El 28 de septiembre, Roque, Garriga y Antoni Feliu acordaron convocar a los estudiantes de bachillerato a manifestarse con la esperanza que se añadiesen a la movilización los universitarios que esperaban el inicio de las clases. La convocatoria fue todo un éxito, sin que llegasen a intervenir las fuerzas de orden público, a primera hora de la tarde, se disolvieron, después de haberse manifestado por el centro de la ciudad. El conde de Cheste, ante la pasividad policial, exigió al rector de la Universidad de Barcelona, Pablo González Hebra, una lista con los nombres de los estudiantes que habían organizado y participado en la manifestación estudiantil. El rector encargó la elaboración de la lista a Josep Coll y Vehí, director del Instituto de enseñanza secundaria (había uno para toda la ciudad y compartía edificio con la Universidad Literaria), siendo enviada al capitán general de Cataluña. Ningún estudiante llegó a ser detenido porque el jefe de los mozos de escuadra, ante la más que posible victoria de los insurrectos, avisó a los estudiantes denunciados. Pero cuando triunfó la revolución, los que estaban en la lista no olvidaron que el rector y el director del Instituto habían sido sus delatores. En consecuencia, reivindicaron y consiguieron que éstos dimitiesen de sus respectivos cargos ${ }^{38}$.

\section{LA REVOLUCIÓN DE 1868 EN LA CIUDAD DE BARCELONA}

Después de la exitosa manifestación de los estudiantes, los revolucionarios barceloneses más exaltados querían comenzar a actuar, pero la Junta revolucionaria clandestina barcelonesa decidió que esperarían a conocer el resultado de la batalla de Alcolea, entre las tropas rebeldes y las gubernamentales para, posteriormente, iniciar la revolución en la capital catalana, aunque venciesen las tropas fieles a Isabel II. Sin embargo, si como era previsible se imponían los rebeldes, la Junta clandestina barcelonesa pretendía sustituir pacíficamente a las autoridades isabelinas de la capital catalana para evitar desmanes y violencia innecesaria.

\footnotetext{
37 Feliu i Codina, A.: ibídem. JANuÉ I Miret, M.: Polítics en temps de revolució. La vida política a Barcelona durant el Sexenni Revolucionari (1868-1873), tesis dirigida por RIQUER, B. de, UAB, 1994, pp. 22-86, y MOLINER PRADA, A.: Revolución burguesa, op. cit., p. 313.

38 Feliu i Codina, A.: El Diluvio, 11, 13, 14 y 15 de diciembre de 1916. Garriga, J.: Memòries d'un liberal catalanista, op. cit., pp. 41-42; JANUÉ, M.: Polítics en temps de revolució, op. cit., pp. 22-24, y de la misma autora La Junta Revolucionària de Barcelona de lany 1868, IUHJVV-EUMO, Vic, 1992, pp. 102-103.
}

Hispania, LXIV/2, núm. 217 (2004) 689-710 
El resultado de la batalla fue favorable a los rebeldes e implicó el rápido derrumbe del régimen político isabelino. La noticia llegó a Barcelona el día 29 de septiembre por la tarde. Finalmente, había llegado el momento de que la Junta dejase actuar a los partidarios de hacer caer «lo existente» ${ }^{39}$.

El día en que se inició la revolución en Barcelona se celebraba una feria en la plaza de San Jaime. Ésta finalizó de manera precipitada, cuando una gran multitud se dirigió hacia el Ayuntamiento. La acción estaba perfectamente organizada y planificada por la dirección clandestina de los revolucionarios. El grupo que entró en el consistorio municipal se dividió en dos cuadrillas. La más numerosa se dirigió hacia el «Saló de Cent», mientras que la menos numerosa, encabezada por Valentí Almirall, buscó el salón donde estaba reunido el pleno del Ayuntamiento que pretendía negociar el traspaso de poderes con una comisión de los revolucionarios. Pero Almirall les expuso claramente su punto de vista cuando «gritó con voz desaforada: iNada de comisiones! iFuera inmediatamente de aquí, si quieren descender ustedes la escalera! iNo sea que la multitud les haga salir a ustedes por el balcón!.» Los concejales allí reunidos obedecieron inmediatamente al joven revolucionario ${ }^{40}$.

El objetivo del grupo que se dirigió al «Saló de Cent» era colgar en los balcones las enseñas de los rebeldes, confeccionadas por el grupo del Café Suizo, e iniciar una ruptura revolucionaria a través de la destrucción de los símbolos vinculados con el régimen político que encabezaba Isabel II. Baldomero Roure. y Napoleón Vilajuana descolgaron el gran retrato de la reina que presidía el salón y lo lanzaron a la plaza desde el balcón para que los que se habían quedado fuera del Ayuntamiento descargaran contra él su rabia. La multitud arrastró el cuadro por gran parte del casco antiguo de la ciudad y posteriormente lo quemó, junto con otros objetos vinculados al régimen político que acaba de ser derrotado y a la dinastía de los Borbones, en un acto de catarsis revolucionaria en la plaza de San Jaime ${ }^{41}$.

Fuente Monge asegura que la mayor parte de las autoridades militares vinculadas al Partido Moderado habrían facilitado activa o pasivamente «la cesión de su puesto a las juntas revolucionarias» e intenta demostrarlo con diversos

39 Feliu i Codina, A.: El Diluvio, 14 y 15 de diciembre de 1916. Altadill, A.: La Monarquía sin monarca, op. cit., pp. 7-9. Sobre la importancia de la batalla de Alcolea véase HEADRICK, D.: Ejército y política, op. cit., pp. 159-160 o FUENTE MONGE, G. de la: Los revolucionarios de 1868, op. cit., pp. 74-81.

40 Feliu i Codina, A.: El Diluvio, 7, 14, 15 y 16 de diciembre de 1916.

41 Feliu i Codina, A.: El Diluvio, 27 de septiembre de 1916, 7, 14 y 16 de diciembre de 1916. AltADILL, A.: La Monarquía sin monarca, op. cit., pp. 7-13; GARRIGA, J.: Memòries d'un liberal catalanista, op. cit., pp. 23 i 40-45; ROURE, C.: Recuerdos de mi larga vida, op. cit., pp. 93-100, nos explican el punto de vista de los revolucionarios barceloneses, mientras que el de los partidarios de la reina se puede encontrar en MASRIERA, A.: Barcelona Isabelina y Revolucionaria, op. cit., pp. 98 i 181-186. Estudios más recientes sobre estos hechos son los de JANUÉ, M.: La Junta revolucionària de Barcelona, op. cit., pp. 18-20, y FUENTE MONGE, G. de la: Los revolucionarios de 1868, op. cit., pp. 92-107 y 111. 
ejemplos, como la actitud del conde de Cheste en «la transferencia pacífica del poder» a los revolucionarios barceloneses. ${ }^{42}$ Sin embargo, no se pregunta como es posible que la «fiesta revolucionaria» en Barcelona fuese el 29 de septiembre (el mismo día que uno de los manifestantes prorrevolucionarios fue muerto por un centinela de la capitanía general), y la proclamación de la Junta revolucionaria provisional el 30, si realmente existió esa colaboración. De hecho, la Junta revolucionaria clandestina de Barcelona intentó constituirse el día 29, al mismo tiempo que la de Madrid pero con la diferencia que la de la capital de España sí que contó con el beneplácito de las autoridades isabelinas ${ }^{43}$. En Barcelona, en cambio, los integrantes de la Junta revolucionaria se dirigieron al Ayuntamiento, el día 29 por la tarde, protegidos por un grupo armado constituido, en su mayor parte, por antiguos militares expulsados del ejército por su liberalismo. Éstos tenían como misión proteger a la Junta e impedir que los incontrolados entrasen en el consistorio municipal o en la Diputación causando destrozos.

La multitud congregada en la plaza de San Jaime, en plena celebración de la "fiesta revolucionaria», se asustaba cada vez que oía ruido de caballos, porque circuló el rumor que Cheste enviaría el ejército para detener y fusilar a los miembros de la Junta. Los rumores tenían una cierta base, ya que envió un regimiento y a los mozos de escuadra para impedir la constitución de la Junta revolucionaria y detener a sus integrantes. La dirección revolucionaria había demostrado su prudencia al frenar los impulsos de los más impacientes, precisamente para evitar la lucha con las tropas gubernamentales y el consiguiente desorden de consecuencias imprevisibles. En estas circunstancias, los miembros de la Junta que se hallaban en el Ayuntamiento pactaron con los oficiales de las tropas enviadas por Cheste una salida digna para las dos partes con la finalidad de no iniciar unas hostilidades inútiles. El acuerdo consistió en que los revolucionarios aceptaron desalojar los edificios del Ayuntamiento y la Diputación, a cambio de que no hubiese ni detenciones ni tiroteos ${ }^{44}$.

Fuente Monge elabora un modelo de transferencia pacífica del poder a las juntas en que las autoridades isabelinas de las grandes ciudades españolas, entre ellas Barcelona, hicieron pública la caída del Gobierno y llamaron a la tranquilidad de la población, a la vez que daban a entender que no se oponían al cambio político. Pero, el 30 de septiembre, Barcelona estaba convulsionada, la población se encerró en sus casas a la espera de acontecimientos, mientras partidas de revolucionarios armados se concentraban en las afueras. La Junta no

42 FUENTE MONGE, G. de la: Los revolucionarios de 1868, op. cit., pp. 80-81.

43 Feliu i Codina, A.: El Diluvio, 18 y 20 de diciembre de 1916. Olivar Bertrand, R.: Así cayó Isabel II, op. cit., p. 211. BOZAL, V.: Juntas Revolucionarias, op. cit., pp. 85-86. MOLINER PRADA, A.: Revolución burguesa, op. cit., pp. 304-307. FUENTE MONGE, G. de la: Los revolucionarios de 1868, op. cit., pp. 76-77.

44. Feliu I Codina, A.: ibídem. MASrierA, A.: Barcelona Isabelina y Revolucionaria, op. cit., pp. 181-186. Roure, C.: Recuerdos de mi larga vida, op. cit., pp. 100-102, y GARRIGA, J.: Memòries d'un liberal catalanista, op. cit., pp. 42-44.

Hispania, LXIV/2, núm. 217 (2004) 689-710 
deseaba que la situación escapase de su control, ya que querían evitar la acción de los demagogos (utilizaban este concepto para desacreditar a los revolucionarios más radicales) que en Barcelona, siguiendo la tradición de las «bullangas», podía concretarse en la destrucción de iglesias, conventos, fábricas y bancos. Por tanto, parecería esperable que el capitán general de Cataluña colaborase con los revolucionarios en la preservación del orden público, pero no fue así. La Junta envió a dos delegados, Jaume Garriga y Gonçal Serraclara, a entrevistarse con Cheste para intentar evitar el inicio de incidentes armados. Éstos fueron recibidos con un simulacro de fusilamiento (Serraclara, un joven de veintisiete años, encaneció de golpe a consecuencia de la tensión $)^{45}$.

Juan de la Pezuela Ceballos, antiguo amigo personal de Narváez, demostró ser un hombre afortunado al no compartir el destino del general Bassa, muerto por una multitud furiosa en 1835. Cheste, el 29 de septiembre, para comprobar el apoyo de los partidarios de la reina, paseó con una escolta muy reducida por la Rambla ocupada por los partidarios de la revolución siendo obsequiado con burlas diversas. En cambio, Fuente Monge interpreta este paseo como. la demostración que el conde de Cheste no se oponía a la transferencia pacífica del poder. Finalmente, el 30 de septiembre, se convenció que la mayor parte de la sociedad barcelonesa estaba al lado de los revolucionarios y abandonó la ciudad para exiliarse en Francia ${ }^{46}$.

Antes de marcharse, transfirió la dirección de la capitanía general al general Bassols, que pronto estableció buenas relaciones con la dirección de los revolucionarios barceloneses. Finalmente, se pudo proclamar la Junta revolucionaria provisional de Barcelona desde los balcones del Ayuntamiento. La dirección revolucionaria de la capital catalana estaba constituida por seis de los integrantes de la anterior Junta clandestina (T. Fabregas, F. Soler y Matas, J. Garriga, F. de P. Roque, F. Pérez Zamora y G. Núñez de Arce) a los que se añadían seis de nuevos (P. Pons, J. Bartra, M. Utrillo, V. Laban, S. Soler y J.M. Torres). La mayoría eran progresistas, mientras que los demócratas republicanos perdían representación en relación con la anterior Junta clandestina. Posteriormente, los barceloneses eligieron la Junta definitiva en las primeras elecciones celebradas por sufragio universal masculino en la ciudad. El triunfo de la revolución se celebró con grandes muestras de entusiasmo cívico que se reflejaron en los cafés y en los casinos, donde se tocaban y cantaban constantemente himnos revolu-

45 Feliu i Codina, A.: El Diluvio, 14, 15, 18, 20 y 22 de diciembre de 1916. Roure, C.: Recuerdos de mi larga vida, op. cit., 1927, pp. 100-102. GARRIGA, J.: Memòries d'un liberal catalanista, op. cit., p. 44. MASRIERA, A.: Barcelona Isabelina y Revolucionaria, op. cit., pp. 202-204, y FUENTE MONGE, G. de la: Los revolucionarios de 1868, op. cit., pp. 81-82.

46 Feliu i Codina, A.: ibídem. GARrugA, J.: ibidem. MASRIERA, A.: ibidem, y Fuente MONGE, G. de la: Los revolucionarios de 1868, op. cit., p. 82, nota 28 .

Hispania, LXIV/2, núm. 217 (2004) 689-710 
cionarios y festivos, mientras continuaba la eliminación de símbolos vinculados al reinado de Isabel II y a la dinastía de los Borbones ${ }^{47}$.

La revolución había triunfado en Barcelona con pocos percances, pero en la capital catalana el cambio político fue más allá de lo deseado por los pronunciados en Cádiz. Así pues, en Madrid, la dirección revolucionaria repartió cincuenta mil fusiles entre las clases populares, mientras esperaban la inminente constitución del gobierno provisional surgido de la revolución. En Barcelona, en cambio, la Junta Revolucionaria provisional no repartió armas, pero ordenó la disolución de los mozos de escuadra (uno de los cuerpos policiales más odiados por las clases populares catalanas), la expulsión de los jesuitas (en una muestra del anticlericalismo de los revolucionarios barceloneses), y la destrucción del Pontón, el barco prisión anclado en el puerto. También impulsaron otras medidas revolucionarias, como el derribo parcial de la Ciudadela (para los revolucionarios catalanes era el equivalente a la bastilla francesa), y el de parte de las murallas, ya que éstas limitaban la expansión urbanística de la ciudad. A su vez, por iniciativa popular, fueron quemadas las casetas donde se cobraban los consumos ${ }^{48}$.

Tras el triunfo de la revolución, algunos dirigentes políticos pasaron por la capital catalana en su camino de regreso del exilio. La Junta revolucionaria aprovechaba estas visitas para organizar manifestaciones de apoyo a la revolución. Sin embargo, la visita más esperada y multitudinaria fue la del general reusense Juan Prim. Éste llegó a la capital catalana el 3 de octubre de 1868 en un barco procedente de Cádiz. La ciudad estaba engalanada para recibir al héroe que había expulsado a la dinastía reinante. Prim pronto advirtió que en Barcelona no se seguía la pauta preestablecida por los pronunciados en Cádiz (cuando acababa de desembarcar, Tutau le pidió que se quitara los símbolos monárquicos de su uniforme). La situación en la capital catalana tenía una orientación verdaderamente revolucionaria, ya que tanto los progresistas como los republicanos barceloneses eran partidarios de una transformación radical del sistema político e institucional español, aunque los primeros se conformaban con la democratización de España y los segundos querían, además, la república y una nueva vertebración del Estado. Esta coyuntura fue aprovechada por los demócratas republicanos para extender el odio que las clases populares

47 Feliu i Codina, A.: El Diluvio, 22 y 27 de diciembre de 1916; Roure, C.: Recuerdos de mi larga vida, op. cit., pp. 102-103. MASRIERA, A.: Barcelona Isabelina y Revolucionaria, op. cit., pp. 204-205. JANUÉ, M.: La Junta Revolucionària de Barcelona, op. cit., pp. 20-24. MOLINER PRADA, A.: Revolución burguesa, op. cit., p. 314. FUENTE MONGE, G. de la: Los revolucionarios de 1868, op. cit., pp. 92-107, 119, 122-146 y la nota 69.

48 MASRIERA, A.: Barcelona Isabelina y Revolucionaria, op. cit., pp. 202-206. JANUÉ, M.: La Junta Revolucionària de Barcelona, op. cit., pp. 20-24. MOLINER PRADA, A.: Revolución burguesa, op. cit., pp. 306-314 y 332-333. FUENTE MONGE, G. de la: Los revolucionarios de 1868, op. cit., pp. 104-117 y 147 , afirma que la Junta de Madrid fue una sumisa intermediaria de los jefes de la revolución.

Hispania, LXIV/2, núm. 217 (2004) 689-710 
barcelonesas sentían contra Isabel II y su régimen político, hacia al conjunto del sistema institucional monárquico ${ }^{49}$.

Prim, desde el balcón del Ayuntamiento de Barcelona, pronunció un discurso en catalán, pensado para dar rienda suelta al entusiasmo de la multitud de varios millares de personas, pero sin contenidos demasiado radicales. Mostró su alegría por el triunfo de la revolución y defendió la necesidad de crear una coalición que reuniese a todas las opciones políticas liberales. Finalmente, pedía a los catalanes serenidad y buen juicio. El discurso de Prim respondía al deseo de los pronunciados en Cádiz de limitar la revolución a un cambio de Gobierno, de monarca y, quizás, de dinastía reinante, pero no de sistema político e institucional. Estos proyectos no encajaban con el ambiente político barcelonés. Así p̀ues, Prim finalizó su discurso con los correspondientes vivas a la soberanía nacional, al ejército y la marina, mientras que la multitud añadía a cada vítor el grito de «iAbajo los Borbones!» que inicialmente el general reusense se negó a repetir, hasta que la reiterada insistencia de los manifestantes le llevó a exclamar «iDoncs bé; abaix, abaix i abaix! [iPues bien; abajo, abajo y abajo!].» La multitud estaba satisfecha y el dirigente revolucionario indignado, hasta el punto que habría dicho a uno de sus amigos, miembro de la Junta revolucionaria, «pero ique han hecho ustedes!.» Para los barceloneses, Prim había encabezado una revolución democrática, mientras que el general reusense únicamente deseaba dirigir un pronunciamiento. La Junta aprovechó la visita de Prim para que éste presidiese una de sus reuniones, donde volvió a defender la necesidad de mantener la unión de todos los liberales con el fin de consolidar la revolución. No obstante, los demócratas republicanos barceloneses se opusieron a la propuesta de Prim ${ }^{50}$.

En definitiva, la situación política de Barcelona no era del agrado del principal líder del Partido Progresista, que habría comentado a su correligionario Agustín Aymar que «isalgo de aquí muy receloso!.» Esta desconfianza habría implicado que no se repartiesen fusiles entre las clases populares barcelonesas. En poco menos de una semana, se rompió la coalición que había acabado con el régimen político isabelino y los demócratas quedaron fuera del nuevo gobierno

49 Feliu i Codina, A.: El Diluvio, 29 de diciembre de 1916 y 2,5 y 8 de enero de 1917,6 y 10 de abril de 1917. Roure, C.: Recuerdos de mi larga vida, op. cit., 1927, pp. 109-112. MASRIERA, A.: Barcelona Isabelina y Revolucionaria, op. cit., pp. 208-210. GARRIGA, J.: Memòries d'un liberal catalanista, op. cit., p. 43. Olivar BerTrAND, R.: Así cayó Isabel II, op. cit., pp. 213-214, y Prim, op. cit., pp. 461-462. Piqueras, J.A.: La Revolución Democrática, op. cit., p. 36. JANuÉ, M.: Polítics en temps de Revolució, op. cit., pp. 24-34. MOLINER PRADA, A.: Revolución burguesa, op. cit., p. 315.

so Feliu i Codina, A.: El Diluvio, 8 de enero de 1917. Roure, C.: Recuerdos de mi larga vida, op. cit., p. 116. Altadill, A.: La monarquía sin monarca, op. cit., 1869, pp. 25-26. MASRIERA, A.: Barcelona Isabelina y Revolucionaria, op. cit., pp. 209-210. MOLINER PRADA, A.: Revolución burguesa, op. cit., p. 315, y FUENTE MONGE G. de la: Los revolucionarios, op. cit., p. 96. 
provisional que, encabezado por Serrano y Prim, impulsó la disolución del movimiento juntista ${ }^{51}$.

\section{A MODO DE CONCLUSIÓN}

El movimiento juntista de 1868 fue el último de ámbito estatal de una larga serie iniciada en 1808. Durante sesenta años, las juntas fueron un instrumento de cambio político eficaz. En 1868, el movimiento juntista barcelonés no era mayoritariamente republicano, ni conscientemente federalista, pero en la capital catalana fomentó la difusión del republicanismo federal. Las memorias de Antoni Feliu y Codina nos han permitido aproximarnos a la actividad revolucionaria barcelonesa, cuando las detenciones y las deportaciones por delitos políticos estaban al orden del día. También aportan claridad al turbulento periodo previo y al inicio de la revolución democrática de 1868 en Barcelona, al explicarnos la composición de la Junta revolucionaria clandestina y algunas de las actividades de los revolucionarios de la capital catalana, comó la difusión de las noticias que llegaban de los pronunciados en Andalucía, a través del Boletín Oficial de la Revolución, o los preparativos para iniciar la revolución en la capital catalana.

La impaciencia de los revolucionarios radicales barceloneses por sumarse a la revolución fue controlada en todo momento por la Junta clandestina, a pesar de la torpe actuación del capitán general de Cataluña, el conde de Cheste. De hecho, el movimiento iniciado como un pronunciamiento en las costas gaditanas se había transformado en una revolución democrática en Barcelona, al cabo de doce días -aunque sus impulsores fuesen una elite política reducida-, tal como observó el mismo Juan Prim cuando visitó la capital catalana. Así pues, los objetivos políticos de una parte substancial de las elites políticas y de la sociedad barcelonesa, durante el periodo previo e inicial de la revolución de 1868, iban más allá de un simple cambio de gobierno. Estos deseos de transformación radical del sistema político e institucional español ayudan a comprender por qué, en poco tiempo, el PRDF se constituyó en la principal fuerza política catalana, mientras que Barcelona se convertía en la capital del republicanismo federal español.

51 Feliu i Codina, A.: ibídem. MASRIera, A.: ibídem. PiQueras, J.A.: La Revolución Democrática, op. cit., pp. 49-50. MOLINER PRADA, A.: Revolución burguesa, op. cit., pp. 334-342, y FUENTE MONGE: Los revolucionarios, op. cit., pp. 149-169.

Hispania, LXIV/2, núm. 217 (2004) 689-710 